\title{
La juventud como lenguaje político: reflexiones a partir de un incendio en un recital de rock
}

\author{
Paula Isacovich \\ Universidad de Buenos Aires \\ Candidata a doctora en Antropología Social (Universidad de Buenos Aires) \\ Docente de la Universidad de Buenos Aires \\ Buenos Aires, Argentina \\ paulaisacovich@gmail.com
}

\begin{abstract}
Resumen En la Argentina, la asociación entre rock y juventud se remonta a mediados del siglo pasado, y esta relación no ha estado exenta de contenidos políticos variables. La discusión académica sobre esta relación se reactivó luego del año 2004, cuando un incendio durante un recital de rock acabó con la vida de numerosos jóvenes. Esto dio lugar a que un conjunto de familiares y amigos de las víctimas, junto con sobrevivientes del trágico evento, se movilizaran exigiendo justicia. El presente trabajo es producto de una investigación antropológica e indaga sobre el lugar de la juventud en el conflicto político desarrollado en torno al incendio, el cual se estructuró entre sujetos adultos. El análisis mostrará cómo los discursos estereotipados sobre los jóvenes construyen y legitiman prácticas y posiciones políticas, expresando metafóricamente problemáticas sociales que afectan a la población sin distinciones etarias. Al mismo tiempo, deja planteadas preguntas sobre lo que los jóvenes, en sus propios lenguajes, tienen para decir.
\end{abstract}

Palabras clave: juventudes, rock, política, lenguajes políticos.

\section{Introducción}

$\mathrm{E}_{\mathrm{p}}^{\mathrm{n}}$ distintos países de occidente, la juventud ${ }^{1}$ irrumpió en la arena pública luego de la Segunda Guerra Mundial, de la mano de la extensión del consumo y la aparición de un mercado y una industria orientados específicamente hacia los jóvenes; de la expansión de los medios masivos de comunicación; del incremento de la matrícula tanto en la escuela media como en la educación superior, entre otros factores (Clarke et al., 2008). En ese contexto, una novedad musical tuvo un papel importante: el rock, que pronto se convertiría en un símbolo internacionalmente asociado a la juventud (Feixa, 2006).

1. Los estudios antropológicos y sociológicos señalan que la juventud no es una etapa natural del ciclo vital con características universales atribuibles a procesos psicobiológicos, sino que es una construcción histórica (Bourdieu, 1990; Chaves, 2009). Distintos trabajos sitúan el surgimiento de un sector juvenil de la población como un fenómeno moderno; marcando cómo desde fines del S. XVIII se institucionalizó y cronologizó el curso de la vida (Groppo, 2000; Souto Kustrín, 2007), es decir que el tiempo vital fue segmentado en etapas y normalizado en relación con una serie de prácticas adecuadas a cada fragmento etario, de la mano de instituciones como la escuela, el servicio militar o los tribunales de menores (Feixa, 2006). 
En la Argentina, la juventud cobró visibilidad como actor social protagónico a mediados del siglo pasado, y allí también el consumo musical ${ }^{2}$ fue colocado como relevante para comprender estos procesos. Según Manzano (2010, p. 31), el rock fue un punto de referencia central para la organización del ocio y el consumo juveniles, dando lugar a la construcción de un sentido de pertenencia generacional y a "formas de sociabilidad enteramente juveniles".

En los años 60, cuando los artistas de rock ya estaban instalados en el mercado discográfico local y en distintos circuitos de entretenimiento, emergieron propuestas identificadas con este género musical, que se oponían a las expresiones del rock desarrolladas hasta entonces en Argentina por considerarlas "música comercial", y se elaboraron nuevas canciones que expresaban críticas sobre distintos aspectos de la vida social (Benedetti, 2008).

Si bien está pendiente una genealogía de las relaciones entre rock y política, entre otros hitos se ha senalado la crítica social y antirrepresiva formulada por jóvenes artistas y espectadores de rock en los años 60 y 70 , y los cuestionamientos que por entonces se formularon en torno a las relaciones entre músicos, música e industria discográfica (Benedetti, 2008; Manzano, 2010). Otro momento destacado fue la transición democrática, en los años 80. La difusión de esta música había recibido un importante impulso en 1982, durante la guerra entre Argentina y Gran Bretaña por la soberanía de las Islas Malvinas, cuando fue prohibida la transmisión de canciones en inglés por radio y televisión. Poco después caía el gobierno militar, y se produjeron algunos estudios sobre esta temática. Una hipótesis fuerte de aquel entonces fue que, ante las limitaciones de la participación política durante la última dictadura, el rock había sido el espacio disponible para la constitución de un movimiento cultural juvenil "contestatario" en esos años (Vila, 1985).

Sin pretender trazar líneas directas entre artistas, consumos, estilos o posicionamientos, es posible identificar algunas continuidades históricas. En un contexto - el de los años 90 - en el cual la juventud era tildada de políticamente "apática", los estudios destacaron el carácter político de prácticas juveniles vinculadas al rock. Por ejemplo, ciertos recitales fueron interpretados como rituales festivos en los que se experimentaban transgresiones controladas y un espacio de crítica sociopolítica en un lenguaje grotesco (Citro, 2008). Otros trabajos mostraron cómo entre las "bandas" de músicos "independientes" se ponde- ró -al igual que en los años 60- como un valor el ser "auténticos" y no "venderse" a las discográficas para alcanzar el éxito comercial (Benedetti, 2008).

Si bien inicialmente el rock permitió unificar y dar visibilidad (o constituir) a la juventud, pronto fue terreno para la elaboración de distinciones sociales y culturales, y se instauraron ámbitos y artistas preferidos por los sectores populares, al tiempo que surgían otros circuitos a los que acudían los jóvenes de mayor poder adquisitivo. Si en los años 60 la "nueva ola" fue el término para designar la novedosa música elegida por un sector de la juventud que las clases altas descalificaban como "mersa"; 3 en los 90 el "rock chabón", referido como un subgénero del rock de inserción barrial, fue estigmatizado también a través de su asociación con un conjunto de prácticas similares a las de las hinchadas de fútbol, como el uso de pirotecnia en los recitales, una modalidad de baile que consiste en golpear los cuerpos denominada "pogo", y el consumo de alcohol y otras sustancias, todas prácticas atribuidas a jóvenes de sectores populares.

Tal como señaló Vila (1996) oportunamente, en particular los primeros estudios pecaron de cierto reduccionismo al atribuir un conjunto de valores y prácticas a los jóvenes de sectores populares, siempre que compartieran un gusto musical, homogeneizando consumos, valores y modalidades de circulación y esparcimiento difícilmente uniformes. No obstante, dejaron sentada la importancia del rock para pensar, en la Argentina, a los jóvenes y sus relaciones con procesos políticos.

La discusión sobre las relaciones entre jóvenes, rock, consumo y política se reactivó a raíz del incendio ocurrido en diciembre de 2004 en el local bailable República de Cromañón durante un recital de la banda de rock Callejeros. La combustión liberó un humo altamente tóxico, el lugar estaba colmado y las puertas de emergencia se encontraban cerradas. Como resultado de estos y otros factores, 194 personas -la mayoría de las cuales eran jóvenes- perdieron su vida. El tema cobró relevancia inmediatamente por la magnitud de la catástrofe y también porque dio lugar a un intenso proceso de movilización centrado en la demanda de justicia. ${ }^{4}$

Asimismo, se constituyó en un foco de interés de no pocos investigadores sociales, en un contexto en el que se multiplicaban tanto los estudios sobre juventudes (Chaves, 2009) como aquellos que focalizaron en distintos procesos de movilización social (Manzano, 2013). 
Signada por un acontecimiento dramático como fue aquel incendio, pero también por las secuelas de una profunda crisis económica que afectó al país especialmente entre 1998 y 2003, en esta ocasión la discusión se centró en cuestiones como las prácticas riesgosas en los recitales de rock y la asociación de estas conductas con el denominado rock chabón-atribuido nuevamente a sectores "vulnerables"- (Wortman, 2005). Estas prácticas y consumos fueron inscriptos en un contexto de incremento de la pobreza y la desocupación, señalando que esos jóvenes habían sido expulsados del trabajo y el consumo, y condenados al "aguante" es decir a la exposición del propio cuerpo a las drogas, al alcohol y al "pogo" (Alabarces, 2008).

Una particularidad de este momento del debate fue la manera en que se atendió a la voz de los jóvenes: distintos trabajos muestran cómo quedaron invisibilizados detrás de las voces y prácticas de los adultos por un proceso de victimización (Crivelli, 2007), de silenciamiento mediático (Souilla, s/f), o bien por su incapacidad para superar el aguante. En este sentido, el rock, fue leído ya no como modo de expresión política, sino como señal de la incapacidad de los jóvenes empobrecidos para construir alternativas (menos dañinas) para sus propias vidas (Alabarces, 2008).

Recuperando las contribuciones reseñadas y a partir de mi trabajo de campo, quisiera proponer una mirada distinta sobre la cuestión juvenil. Considero que los sentidos sobre la juventud han sido centrales en este conflicto político y en particular en el debate sobre las responsabilidades en torno a Cromañón. Es por ello que me parece relevante la atribución de prácticas riesgosas o características socioeconómicas a los jóvenes - las cuales contrastan con la heterogeneidad advertida en el trabajo de campo etnográfico-, fundamentalmente porque en la discusión sobre Cromañón habilitaron distintos posicionamientos.

A mediados de 2006 comencé una investigación ${ }^{5}$ centrada en el conflicto que se originó tras el incendio. Estaba interesada en reflexionar sobre militancia juvenil, y el caso parecía adecuado considerando la asociación histórica que ha existido en Argentina entre rock y juventud, así como la presencia de numerosos jóvenes sobrevivientes del incendio en las actividades públicas relacionadas con Cromañón. Sin embargo, desde los primeros acercamientos observé que los principales referentes y voceros del conflicto no eran jóvenes, sino adultos, ya fueran padres, madres, funcionarios de gobierno, periodistas, analistas u otros. No obstante, en este proceso político los jóvenes eran referentes discursivos permanentes.

En este artículo, analizo la construcción de este conflicto atendiendo a cómo los distintos modos de pensar lo juvenil se constituyeron en herramientas de la disputa política. Para ello, recupero propuestas teóricas que destacaron la relevancia de analizar los lenguajes políticos movilizados para comprender los procesos históricos que les dan sentido (Palti, 2007), ${ }^{6}$ así como otras que advirtieron en las apelaciones a la juventud los indicios lingüísticos de procesos sociales más amplios (Durham, 2011). Para eso, desplazaré el foco de los jóvenes en sí mismos, para analizar cómo estos operan en los discursos sobre Cromañón, imprimiendo sentidos a prácticas y demandas.

En las páginas que siguen presentaré brevemente el caso destacando elementos de la discusión sobre las responsabilidades en torno al incendio. Luego veremos cómo las distintas miradas sobre la juventud se constituyeron en herramientas en la puja por imputar esas responsabilidades a unos u otros. El recorrido habilitará una lectura sobre las problemáticas que fueron colocadas en escena apelando a imágenes donde la juventud operó como metáfora de la vulnerabilidad social. Finalmente, procuraremos preguntarnos dónde están y qué dicen los jóvenes más allá de los discursos que los nombran.

\section{Del incendio al conflicto político}

El 30 de diciembre de 2004, durante un recital de rock, se produjo un incendio en el boliche República de Cromañón, originado por un artefacto pirotécnico que encendió materiales inflamables dispuestos en el techo a modo de aislantes acústicos. El local había sido habilitado pese a que no cumplía con algunos requisitos en materia de seguridad señalados en normas vigentes. ${ }^{7}$ Entre otras irregularidades, el material que inició el incendio no era ignífugo; la capacidad del local estaba sobrepasada entre un 100 y un $500 \%$

\footnotetext{
5. En este artículo se reelaboran aspectos de mi tesis de licenciatura en Antropología Social que versó sobre el proceso asociativo y la construcción de demandas configuradas a partir del incendio del boliche República de Cromañón.

6. Elías Palti revisó procesos políticos del siglo XIX mexicano desde una perspectiva de historia intelectual, indagando en los lenguajes políticos de la época, y marcando una distinción entre lenguaje e ideología, en tanto el primero es siempre semánticamente indeterminado porque permite afirmar tanto una cosa como la contraria. Los lenguajes están históricamente configurados y los sentidos que expresan pueden resultar híbridos en cuanto a los contextos que los informan (Palti, 2007).

7. En los juicios penales en curso por el incendio de Cromañón se investigó el incumplimiento de diversas normas. Entre ellas la Ordenanza n. ${ }^{\circ}$ 50250, que regula la prevención de incendios en locales bailables y establece una serie de instancias necesarias para su habilitación, como la certificación anual por la Superintendencia de Bomberos de la Policía Federal, vencida al momento de realizarse el recital. Fuente: Presentación de la Fiscalía de Instrucción en el marco del Juicio Penal que investigó el incendio. Disponible en: <http://www.quenoserepita.com. ar/introduccion_judiciales>. Acceso en: 12 feb. 2012.
} 
por sobre los 1031 espectadores que permitía la habilitación del boliche, y la puerta de emergencia se encontraba cerrada con cadena y candado.

Como producto del incendio, murieron 194 personas, la mayoría jóvenes, y cientos de los sobrevivientes cargan con daños físicos crónicos por la inhalación de los gases tóxicos que produjo la combustión.

Al día siguiente del incendio hubo una importante afluencia de personas a las inmediaciones del boliche. Eran allegados a quienes habían participado del recital, y reclamaban centralmente justicia. Lo mismo sucedió el $1^{\circ}$ de enero de 2005 , pero ese día la concentración se desplazó hacia Plaza de Mayo, principal centro político de la ciudad y del país. A partir de aquella iniciativa se sucedieron numerosas y diversas convocatorias. Especialmente durante las primeras movilizaciones era abrumadora la presencia de jóvenes.

Distintas agencias estatales intervinieron en cuestiones relacionadas con el incendio en aquellos primeros días: el empresario a cargo del evento fue detenido el 31 de diciembre de 2004, se dispuso una línea telefónica gratuita para dar información a quienes buscaran familiares, se prohibieron los recitales en discotecas, se estableció la obligación de cerrar hasta obtener una nueva habilitación para todos los locales bailables de la ciudad y se lanzó un subsidio para los sobrevivientes -que inicialmente fue a cambio de no iniciar juicios contra la ciudad y luego sin condicionamientos. Por su parte, la Legislatura de la Ciudad de Buenos Aires interpeló al jefe de Gobierno del distrito para que diera explicaciones por las acciones realizadas en la "prevención" del hecho.

Estos múltiples procesos en torno a este acontecimiento fueron dando lugar a la formación de un espacio político de disputa y negociación en torno al incendio y sus consecuencias, centrado en la identificación y definición de las causas que lo originaron y de sus responsables. En ese espacio, se destacaban los jóvenes - de modos que analizaremos a lo largo del artículo- y también los organismos de Gobierno, especialmente los de la órbita local. Por ejemplo, se cuestionaron las acciones gubernamentales en temas tales como las habilitaciones y el control del funcionamiento de locales bailables o el sistema de emergencias médicas de la ciudad, tanto anteriores al incendio como durante la emergencia.

Mientras tanto, los medios de comunicación difundían distintas versiones de los hechos, que coincidían en que la magnitud del daño pudo haberse evitado. Algunos calificaron el evento de "tragedia", otros de "masacre", y, en estos nombres asignados a los sucesos, dejaron translucir lecturas sobre las res- ponsabilidades en general y sobre el lugar de los jóvenes en particular.

Entre los señalados como responsables del incendio y las muertes, se mencionó al empresario de espectáculos a cargo del boliche, a quien encendió la bengala, a los músicos y a las autoridades de la ciudad de Buenos Aires, en las figuras de varios funcionarios y agentes estatales de distintas áreas de gobierno y también de los cuerpos de policías y bomberos. En esos debates estaban en juego posicionamientos morales, pero también procesos jurídicos, incluyendo causas penales y civiles, contra todos los señalados, y también un juicio político contra el entonces jefe de Gobierno del distrito, quien resultó destituido de su cargo en marzo de 2006 por ese proceso.

Durante los primeros días de 2005, la agenda de discusiones en torno al incendio se estableció fundamentalmente desde los medios de comunicación, por medio de notas periodísticas, informes e imágenes, las cuales estuvieron centradas en temas tales como las características del local y de la situación al momento del incendio, el accionar de policías, bomberos, agentes de salud, y también en el uso de bengalas en lugares cerrados, el consumo de alcohol y otras prácticas que fueron definidas como riesgosas y atribuidas a los jóvenes que asisten a recitales de rock. Así, con la intervención pública de funcionarios de Gobierno, dirigentes políticos de partidos opositores al Gobierno, músicos, empresarios de espectáculos y familiares de víctimas, la discusión pública sobre lo sucedido en Cromañón se elaboró en torno a los jóvenes y su responsabilidad.

En las primeras movilizaciones que se realizaron por Cromañón, los manifestantes demandaron por medio de cánticos, pancartas y otros modos de expresión, distintas cuestiones como atención médica y psicológica a las víctimas; condiciones de protección a los usuarios de espacios públicos; la renuncia y el juicio a una serie de funcionarios de la ciudad de Bs. As, y el castigo al empresario.

En el curso de aquel año se fueron conformando asociaciones de familiares, amigos y sobrevivientes de Cromañón (expresión que habitualmente designa a víctimas y allegados que participan de acciones generadas por los grupos). Estos agrupamientos se constituyeron en actores centrales del conflicto posterior -que aún perdura-, interviniendo en la discusión sobre las responsabilidades en torno al incendio y en los procesos judiciales que se originaron allí.

En el próximo apartado, indagaremos sobre la etapa inicial de aquella discusión, atendiendo especialmente al modo en que los jóvenes fueron colocados. 


\section{Juventud y rock en el debate sobre las responsabilidades}

\author{
Si no hacemos algo para cambiar las cosas nos \\ convertiremos en cómplices de los empresarios \\ inescrupulosos, de los funcionarios $\operatorname{coimeros}^{8} \mathrm{y}$ \\ de algunos inadaptados que vienen a nuestros \\ recitales a descargar su agresión con pirotecnias. \\ (Carta enviada por un músico de rock, Diario \\ Clarín Edición Digital, 4 de enero de 2005)
}

Durante los días posteriores al incendio se difundió por los medios periodísticos cuantiosa información sobre este caso, complementada con notas de opinión y entrevistas que contribuyeron a establecer los términos iniciales del debate público. Por ejemplo, el 31 de diciembre de 2004 el matutino $\mathrm{La} \mathrm{Na}$ ción tituló un artículo: "Tragedia en un recital: 169 muertos", y destacó que la noche del 29 de diciembre, en otro recital del mismo grupo musical en Cromañón, había escuchado decir al empresario del boliche:

"Chicos, no tiren bengalas ni petardos. Tengamos la noche en paz. Esto es un recital de rock y tiene que ser una fiesta. El techo está acondicionado para que se escuche mejor la música y tiene una acústica especial que es inflamable. Y el humo de las bengalas es cancerígeno. El que tira petardos tiene instinto criminal..."

Hubo silbidos e insultos hacia el orador. La respuesta fue la obvia en ese grupo de poco más de 3000 jóvenes.

Por su parte, el diario Clarín reeditó el 31 de diciembre una entrevista realizada con anterioridad al empresario, a quien presentó destacando su experiencia como productor de espectáculos y su posición de "emblema del circuito under rockero". 9,10 También la banda de rock que se presentaba ese día tuvo una fuerte presencia en los medios de comunicación, en notas como: "Las bengalas, una tradición desde que Callejeros inauguró Cromañón" (Clarín, edición digital del 31 de diciembre de 2004). En estos artículos, el énfasis estaba puesto en inscribir a estas personas en una tradición roqueera asociada a prácticas de descuido o de rebeldía. Pocos días después, las crónicas de la movilización del 2 de enero destacaron el relato de los enfrentamientos entre un grupo de jóvenes "de no más de 25 años" con la Policía Federal (Clarín, edición digital del 2 de enero de 2005).

Otro tema recurrente en esos días fue la guardería infantil que, según se afirmó, funcionaba clandestinamente en el baño del local. Por ejemplo, el suplemento femenino de otro diario publicaba un conjunto de artículos titulado: "Esta sociedad, estas familias", en el cual señalaba: "Son muchas las voces acusadoras contra quienes habían elegido disfrutar de la banda de sus amores junto a sus hijos e hijas pequeños. [...] esos padres son adolescentes que no pueden volverse adultos por el sólo hecho de parir" (p. 12, Suplemento Las12, edición digital del 7 de enero de 2005).

Con artículos acerca de los recitales de rock, el uso de pirotecnia, la banda Callejeros, la presencia de niños en el boliche, el local de Cromañón o la personalidad y trayectoria del empresario, los medios de comunicación resaltaron el espacio en el cual se delinearon los ejes y los márgenes de la discusión, focalizando en cuestiones como el desarrollo de conductas de riesgo en los recitales de rock, o la violencia y la responsabilidad juveniles. Movilizadas por familiares de las víctimas, músicos, funcionarios y dirigentes políticos, académicos o periodistas, las opiniones y posicionamientos se multiplicaban, y las referencias a los jóvenes enfatizaban los riesgos que generaban sus conductas para sí mismos y para otros. Esta imagen de la juventud, como pretendo mostrar, fue alternándose con otras que sirvieron de sostén a distintos posicionamientos en el debate que procuró determinar las responsabilidades sobre lo sucedido.

La supuesta guardería nunca existió, algo que fue enfatizado por los familiares de las víctimas en un intento de desligar a los jóvenes de la responsabilidad por las muertes. Y tampoco fue confirmado que la bengala hubiera sido encendida por una persona joven. No obstante, ambos temas fueron dados por hechos y discutidos largamente las primeras semanas de 2005, conformándose así un campo discursivo que naturalizó una visión de los jóvenes como peligrosos, en particular de aquellos que son padres y madres.

Esta naturalización habilitó tanto propuestas que culparon a dichos jóvenes, como otras que los victimizaron. Una de ellas fue formulada por un músico de rock, quien afirmó que a esos padres "el Estado debería hacerles juicio", que el hecho no pudo ser previsto ni por el empresario ni por la banda, y que en cambio "sucedió por la ignorancia de jóvenes subalimentados y acostumbrados a la agresividad" (Revista Radar, 14 de enero de 2005).

\footnotetext{
8. En lenguaje coloquial coima equivale a soborno.

9. Su biografía se vincula desde hace más de 30 años al rock, como empresario, y también como artista. Por ello, su lugar en este conflicto puede pensarse relacionado al de los jóvenes, en tanto se lo juzga enfatizando su trayectoria roquera, mientras que se asocia el rock a lo juvenil. No obstante, en cuanto adulto, su responsabilidad fue considerada de otra magnitud.
}

10. El término under refiere a un circuito de espectáculos artísticos que se constituyó, tal como señaláramos para el rock, por oposición al circuito considerado "comercial". 
El denominado "rock chabón" fue otro tópico destacado en aquel momento. Un artículo académico asoció este estilo musical con una tradición dentro del rock que atraería a los sectores más empobrecidos y vulnerables, en oposición a un rock más elaborado, elegido por sectores acomodados. A partir de esta caracterización de la escena, se preguntó por las estructuras que condicionaron a un sujeto que cometió, más allá de su voluntad, la "acción irracional, irresponsable" de arrojar una bengala (Wortman, 2005). Desde este lugar, se reclamó la intervención adulta, afirmando que estos jóvenes han sido expulsados de la ciudadanía, no tienen futuro, y tampoco tienen la capacidad de generarse alternativas (Alabarces, 2008).

Estas miradas suponen, por un lado, que los jóvenes de Cromañón son peligrosos, pero (¿o por qué?) también son pobres y vulnerables. Al mismo tiempo, no son reconocidos como personas completas, sino que se afirma que no pueden solos, y que los adultos deben velar por ellos.

En suma, se fue configurando una lectura de los hechos que estableció una asociación entre rock-jóvenes-bengalas-incendio, en la cual los jóvenes fueron colocados, al mismo tiempo y con diferentes énfasis, como responsables del incendio y víctimas de su propia incapacidad para asumir responsabilidades. Luego, esos sentidos de juventud fueron movilizados en el proceso analizado como nociones legitimadoras de demandas y también de posiciones políticas en disputa.

Más allá de la discusión sobre la pertinencia de asociar el "rock chabón" con un sector socioeconómico, me interesa marcar cómo, en el contexto del debate inicial de Cromañón, cuando primó una lectura de las causas del incendio que imputaba a los jóvenes roqueeros, el énfasis fue colocado en aquellos provenientes de "sectores empobrecidos y vulnerables". Como veremos, esto no fue homogéneo a lo largo del proceso.

En cuanto a los familiares y sobrevivientes, existe un discurso común de defensa de las víctimas donde el joven es colocado como un ser irresponsable al que no se puede culpar por lo sucedido. No obstante, estas ideas se tensionan en el desacuerdo que muestran acerca de la responsabilidad de quien arrojó la bengala y de la banda de rock. Por ejemplo, Clara, abuela de un joven fallecido en Cromañón, me comentó más de una vez que para ella el proceso penal no podía tratar de la misma manera a todos los imputados porque "él es un viejo empresario, los chicos de la banda intentan hacer un mango". 11 Según esta abuela, el "viejo" es responsable, los músicos son "chicos"12 y por lo tanto no podrían responder plenamente por sus actos.
Por otra parte, mientras algunos familiares y sobrevivientes se oponen a los recitales de rock, otros han impulsado la conformación de un espacio que nuclea músicos, para demandar que el Estado garantice la organización de recitales con las condiciones necesarias para el cuidado del público.

Estas tensiones manifiestan cómo distintas lecturas sobre el rock, los jóvenes y las responsabilidades operan como construcciones semánticas que sostienen distintas prácticas en la búsqueda de justicia por las víctimas del incendio, como culpar o no a los músicos, y sostener o impugnar los conciertos.

A continuación analizaremos cómo operaron estos sentidos de juventud en el juicio político desarrollado contra el entonces jefe de Gobierno.

\section{El debate sobre las responsabilidades en el contexto del juicio político}

Desde los primeros días posteriores al incendio fueron colocadas en el centro del debate sobre las responsabilidades acciones estatales como las relativas al control de locales bailables, el operativo de emergencia de aquella noche, entre otros aspectos.

La máxima autoridad política de la ciudad de Buenos Aires fue señalada rápidamente como parte responsable de la masacre que ocasionó el incendio. En ese marco, diputados de la Legislatura de la Ciudad, en su mayoría de partidos opositores, gestionaron una interpelación al jefe de Gobierno y otros funcionarios del poder ejecutivo e iniciaron un proceso para investigar la responsabilidad que podía caberles a funcionarios del Gobierno de la ciudad en esos hechos (Resolución n. ${ }^{\circ}$ 624/2005, Legislatura de la Ciudad de Buenos Aires).

Unos meses después, la comisión produjo un informe en base al cual el jefe de Gobierno fue acusado de una serie de cargos vinculados a los cambios realizados durante su gestión en el Área de Control Comunal, encargada de la habilitación y el control de locales bailables; al funcionamiento del dispositivo que el Sistema de Atención Médica de Emergencia (SAME) debió implementar la noche del 30 de diciembre; también al funcionamiento de la Morgue en relación con las dificultades y demoras que padecieron los familiares que tuvieron que identificar cuerpos de personas fallecidas. Por ejemplo, se consideró que, de haberse distribuido los heridos a los hospitales de acuerdo a un criterio más ajustado a la gravedad

11. En lunfardo, mando equivale a dinero

12. Al momento del incendio de Cromañón, la mayoría de los integrantes de Callejeros tenía entre 20 y 30 años. 
de sus respectivos cuadros de salud, podían haberse salvado vidas. También se acusó al jefe de Gobierno de haber despedido o reubicado a numerosos inspectores dejando a la ciudad sin posibilidades de ejercer un control adecuado (Informe de la Defensoría del Pueblo de la Ciudad de Buenos Aires).

El juicio político tuvo lugar a comienzos de 2006. Los diputados fueron designados para integrar la Sala Acusadora o bien la Sala Juzgadora. Luego de que los primeros formularan la acusación, aquellos que oficiaron de jueces emitieron sus fallos. El entonces jefe de Gobierno resultó destituido de su cargo con 10 votos a favor, 4 en contra y 1 abstención. Si bien no hay espacio aquí para analizar el juicio, lo dicho es pertinente para comprender las apelaciones a la juventud en este marco. Por ejemplo, la parte acusadora planteó: "A los chicos de Cromañón los mató la corrupción [...] fue resultado de la complicidad entre empresarios de la noche y el Gobierno, en un sistema de no control y corrupción estructural, en manos de funcionarios de primera línea [...]" (Alegato Final de la Acusación, Acta de la sesión especial de la Legislatura de la Ciudad de Buenos Aires, 28 de febrero de 2006).

Por su parte, la estrategia defensiva tuvo dos líneas argumentales: la principal estuvo orientada a pedir la anulación del proceso acusando a los diputados de intentar un golpe institucional. La otra se desarrollaba en torno a las medidas llevadas a cabo en las áreas vinculadas a los cargos de mal desempeño formulados en su contra: Control Comunal, el SAME y la Morgue. Este argumento se orientaba a explicar que Cromañón sucedió no por lo hecho en el gobierno, sino pese a ello.

El alegato final de la defensa culminó con dos propuestas centradas en el cuidado de la juventud: "Tenemos que dialogar mucho con nuestros jóvenes, porque es necesario que ellos también encuentren motivos para cuidarse" y "El mejor homenaje que les podemos hacer a las víctimas es cuidar a nuestros jóvenes, y especialmente a los sobrevivientes" (Alegato Final de la Defensa, Acta de la sesión especial de la Legislatura de la Ciudad de Buenos Aires, 28 de febrero de 2006).

También los diputados que actuaron como jueces en el proceso se centraron en los jóvenes. Por ejemplo, uno de quienes votaron a favor de la destitución afirmó: "Yo quiero que mis gobernantes garanticen razonablemente la vida de mis hijos [...] porque los hijos de Cromañón también son nuestros hijos". Por su parte, una diputada que votó por la absolución, planteó la necesidad de que "se comiencen a abrir discusiones... para que nuestros chicos entiendan lo que nos importan sus vidas y para que los adultos entendamos que cada vez que vemos un chico en la calle puede ser nuestro hijo... Responsables somos todos."
(Ambas citas extraídas de: Lectura de los votos de los diputados miembros de la Sala Juzgadora, Acta de la sesión especial de la Legislatura de la Ciudad de Buenos Aires, 7 de marzo de 2006).

Tanto la acusación como la defensa y los diputados que tomaron posición de uno u otro modo, hicieron referencia a imágenes estereotipadas de los jóvenes como vulnerarles, incompletos, imposibilitados de cuidarse solos. A partir de estas imágenes, el debate sobre la responsabilidad ante las muertes ocasionadas en Cromañón se estructuró, en el marco del juicio político, en torno al cuidado de la vida de la juventud.

Entre quienes actuaron a favor de la destitución, el descuido fue responsabilidad del Estado, y en particular del entonces jefe de Gobierno, sea por falta de prudencia o razonabilidad, sea por actos de corrupción y "descontrol" deliberado. Para quienes impulsaron la absolución, el descuido fue una responsabilidad colectiva, de la que los mismos jóvenes fueron, en alguna medida, responsables. Sin embargo, la responsabilidad que les cabe no es similar a la de los adultos. En cambio, lo que se señala es su incapacidad para cuidar de sí mismos y de los demás.

Tomado de conjunto, el proceso estudiado muestra un conflicto político que se estructuró en torno a sentidos de juventud movilizados para el establecimiento de posiciones, demandas y acciones políticas, tales como juzgar a un jefe de Gobierno. Es en ese sentido que propongo pensar lo joven como núcleo de un lenguaje político que se configuró en un conflicto específico, pero a la luz de procesos históricos que ligan a los jóvenes con el rock y también con la política. El concepto de lenguaje político supone pensar las categorías en relación, analizarlas en conjunto y considerar la manera en que permiten expresar posiciones contrapuestas (Palti, 2007), algo que sucedió en este proceso donde la apelación a la juventud habilitó tanto posiciones que culparon a los jóvenes como otras que los victimizaron, y del mismo modo posicionamientos diversos respecto de actores como los funcionarios de Gobierno.

Por otra parte, en estos parlamentos se modifica la caracterización de la juventud. Si en los inicios del proceso, cuando el debate sobre Cromañón se estructuró en torno al rock y los jóvenes, y se centró la mirada en su irresponsabilidad y peligrosidad, las referencias a ellos aparecieron asociadas al embarazo adolescente, la mala alimentación, la insuficiente educación y al "rock chabón". En cambio, en el proceso judicial analizado, estas referencias -atribuidas a "sectores empobrecidos"- se diluyen y quedan los chicos despojados de marcaciones de clase.

Este análisis habilita preguntas acerca de quiénes son los jóvenes denunciados y quiénes son aquellos que, en los discursos de los legisladores, aparecen 
como víctimas. En otras palabras, acerca de quiénes son los sujetos de derecho político, los ciudadanos que deben ser protegidos por el Estado.

\section{La juventud como metáfora}

La cuestión de la vulnerabilidad y el cuidado de los jóvenes habilitaron, en el marco del juicio político, una discusión acerca de la responsabilidad del Estado sobre la vida de los "ciudadanos". Si bien el debate se desarrolló en torno a la juventud, esta funcionó como metáfora de una ciudadanía expuesta a riesgos de vida, bien por corrupción, descontrol, falta de prudencia de los funcionarios estatales, negociados empresarios, o bien por irresponsabilidad en las propias prácticas de los sujetos. Así, el lenguaje político movilizado en este conflicto permitió expresar un conjunto de tensiones sociales y demandas que no necesariamente involucran especialmente a jóvenes.

Una de las consignas que los grupos de familiares enarbolan con más intensidad afirma: "Todos somos sobrevivientes". Al mismo tiempo, distintos documentos elaborados por ellos hacen referencia a "otros cromañones" en referencia a cuestiones tan diversas como el estado edilicio de las escuelas estatales, la prescripción de la causa por el atentado contra una mutual judía ocurrido en 1994, o el incendio de un taller textil donde trabajaban inmigrantes ilegales. De forma relacionada, para los agrupamientos, las víctimas son "los pibes de Cromañón". La unidad de todos estos casos se construye desde la interpretación de que empresarios o funcionarios priorizan los réditos económicos por sobre la vida de las personas, y de que ante todos estos casos prima la "impunidad". Y en demanda de justicia, declaman: "ni la bengala ni el rock and roll, a nuestros pibes los mato la corrupción".

Estas consignas y términos articulados en el discurso de los familiares conforman una construcción semántica que se sostiene en una identificación con los fallecidos o sobrevivientes de Cromañón, y en su definición como jóvenes. En el registro del joven como ser incompleto que requiere cuidados, al identificar a toda la sociedad con los jóvenes, abonan su denuncia de que todos corremos riesgos por causas evitables vinculadas a negocios, actos de corrupción o negligencias en la gestión pública o en la administración de justicia. Nuevamente, los jóvenes son referidos como metáfora de la vulnerabilidad social, la cuestión etaria es puesta en juego para legitimar las demandas impulsadas por los agrupamientos.

En este punto, quiero retomar la sorpresa inicial acerca de la construcción de Cromañón como un conflicto de jóvenes. Ellos son colocados en el centro de los distintos discursos sobre el caso, se constituyen en el argumento central de numerosas deman- das y son referidos como demandantes. Sin embargo, la observación de las actividades organizadas por los grupos de familiares, amigos y sobrevivientes de Cromañón muestra que la mayoría de los participantes que ocupan los espacios de mayor visibilidad son adultos.

Luego del incendio se conformaron diversos agrupamientos, algunos nuclearon familiares, otros sobrevivientes, o bien ambos, y también amigos de las víctimas. Sus agendas presentan objetivos y actividades diversas. Algunos consideran que lo central es coordinar la acción en las querellas judiciales, sosteniendo que los sobrevivientes no deberían participar de esas instancias. Otros, que sí intentan incorporar jóvenes sobrevivientes a sus actividades, se concentran en garantizarles asistencia mediante terapias, seguimiento de salud, gestión de subsidios. Fueron pocos los agrupamientos que valoraron la participación de los sobrevivientes y propusieron un mayor protagonismo juvenil. Uno de ellos es Memoria y Justicia Por Nuestros Pibes, el grupo del cual estuve más cerca durante mi trabajo de campo. Según cuentan algunos de sus integrantes, desde sus inicios realizaron talleres reflexión y de murga para pensar qué hacer ante lo sucedido. Así se conformó Los que Nunca Callarán, murga conformada por sobrevivientes y por la madre de una víctima de Cromañón.

Con el tiempo, el lugar de los jóvenes en la agenda cotidiana de los familiares, amigos y sobrevivientes de Cromañón quedó acotado a las marchas mensuales y a la participación en la murga. Así, padres y madres desplazaron a los pibes a un lugar de menor visibilidad. Eso no quiere decir que los jóvenes no tomaran parte en los grupos, en las decisiones cotidianas, o que no fueran valorados. Pero lo cierto es que no se los veía en momentos/lugares como los escenarios, las cámaras de televisión.

Lo que me interesa señalar es cómo las apelaciones a la juventud referidas la colocan como índice social (social shifter) de otros aspectos que permiten comprender los contextos en los cuales los jóvenes son nombrados. Es la propuesta de estudios antropológicos acerca de los jóvenes en el espacio político del África poscolonial, quienes recuperaron un concepto proveniente de la lingüística referido a un término indexical que:

tiene la capacidad de... poner en la conciencia discursiva las características metalingüísticas de la conversación; es decir, que puede ir más allá de las relaciones inmediatas que se están negociando y llamar la atención sobre la estructura y las categorías que producen o permiten el encuentro. Cuando las personas apelan al concepto de juventud en una situación, se sitúan a sí mismas en un paisaje social de poder, derechos, expectativas, y relaciones, indexicalizándose tanto a sí mismas como a la topología de ese paisaje social. (Durham, 2011, p. 61) 
En este sentido, podemos repensar los discursos citados de familiares y funcionarios para identificar dos cuestiones relevantes para comprender la paradoja que dio lugar a esta reflexión: la invisibilidad de los jóvenes en un conflicto centrado en ellos. Por un lado, los sentidos de juventud puestos en juego, al tiempo que dan lugar a la demanda de cuidados para ellos, sitúan a quienes enuncian las demandas en el lugar de poder que implica la adultez en este contexto, en contraposición a la imagen estereotipada de los jóvenes como vulnerables (incompletos, peligrosos, inseguros). Esta relación opera concentrando el protagonismo en los familiares (adultos, padres y madres) por sobre los sobrevivientes (jóvenes).

Por el otro lado, el acto de movilizar estos sentidos contribuye a construir la posición de autoridad desde la cual se formulan las demandas, que no supone exclusivamente adultez, sino también parentesco, reelaborando así una fuente de legitimación de demandas relevante en las últimas décadas en Argentina. ${ }^{13} \mathrm{Y}$ esta autoridad resulta significativa para posicionar a los familiares, sobre todo a los padres y madres, frente a los funcionarios y agencias estatales.

Entonces, los jóvenes en Cromañón son básicamente las víctimas que sostienen, en el discurso, las demandas de los grupos. Tal vez el carácter de metáfora por la cual se expresaron distintas tensiones sociales y demandas ayude a entender su posición en las actividades: si los jóvenes son incompletos, los actores socialmente asociados al cuidado -como la familia o el Estado- pueden hablar por ellos.

\section{Epílogo: los pibes detrás de la metáfora}

A mediados de 2009 uno de los juicios penales que investigan las responsabilidades en el incendio y que aún siguen en curso llegó a la sentencia en primera instancia. En esa oportunidad se movilizó e hizo visible un importante número de jóvenes seguidores de Callejeros, reclamando frente a los tribunales de justicia la inocencia de los músicos: agitaban banderas, cantaban canciones de la banda de rock, y también se enfrentaron cuerpo a cuerpo con los familiares y con la policía. Desde entonces, varios agrupamientos juveniles mantienen una cierta actividad pública por esta misma causa: la defensa de la banda de rock. ${ }^{14}$
Si bien no he seguido ese proceso, la referencia remite al inicio de este texto, donde la apelación a la historia de la juventud en Argentina permitió visualizar cómo la constitución y delimitación de este sector de la población estuvo atravesada por la difusión del rock y su apropiación por numerosos jóvenes. Asimismo, contribuyó a iluminar tensiones en torno a circuitos y artistas de rock que fueron colocados como criterios de distinción con un contenido de clase.

Estas tensiones se actualizaron en el conflicto analizado aquí, cuando el consumo de rock fue activado como eje y fundamento de una imagen estereotipada de la juventud peligrosa, descuidada, incompleta. En aquel primer momento, las referencias al desempleo, la materpaternidad adolescente, los barrios populares, el pogo y las zapatillas confluían en la delimitación de un segmento de la juventud definido no sólo en términos de edad, sino también de clase social.

Mientras que el rock chabón fue movilizado en pos de acusar a los y las jóvenes como parte responsable por las muertes que causó el incendio, el reclamo de cuidado de la vida de la juventud que sostuvo buena parte de los posicionamientos en torno al juicio político al jefe de Gobierno de la ciudad se elaboró sin apelar a aquellas marcaciones clasistas. En cambio, las imágenes referidas contraponían el lucro al cuidado, y los y las jóvenes eran definidos más por su vulnerabilidad que por sus prácticas peligrosas.

Por otra parte, esas referencias contribuyeron a la construcción de un posicionamiento de los familiares y funcionarios intervinientes en cuanto adultos. En otras palabras, la apelación a la juventud habilitó para ellos una posición de poder definida en términos etarios.

La relevancia de las prácticas culturales para la constitución y también para la comprensión de la juventud ha sido señalada por numerosos estudios sociales (Clarke et al., 2008; Feixa, 1998) y así también en particular para el caso argentino (Chaves, 2009; Manzano, 2010). Como señalamos, el rock se ha destacado entre tales consumos.

Pero en esta ocasión, el rock no fue solamente un instrumento de sociabilidad e identificación para los y las jóvenes, sino que fue más bien un elemento nodal de un lenguaje por medio del cual se elaboraron y confrontaron posicionamientos en un conflicto. Dicho de otro modo, el rock-que había sido un lenguaje juvenil- fue apropiado para construir sentidos sobre los jóvenes, intervenir sobre sus vidas y formularle demandas más amplias al Estado.

13. Desde finales de la década del 70 se multiplicaron agrupamientos sociales de familiares de víctimas entre los cuales destacan las Madres de Plaza de Mayo, entre otros. Para un análisis de las apelaciones de las víctimas de Cromañón a esa modalidad de legitimación política, véase Isacovich (2010).

14. En aquel contexto, los familiares, amigos y sobrevivientes de Cromañón dispusieron un momento especial de la marcha mensual posterior para que los sobrevivientes leyeran un documento de su autoría, escrito por y para jóvenes. Aun en esa circunstancia en la que los jóvenes cobraron mayor visibilidad, ese espacio fue habilitado por los adultos. 
A modo de cierre, quisiera dejar abierta una cuestión abordada intensamente por estudios recientes sobre juventud y política en Argentina. Un postulado que recorre varios trabajos sostiene que la década de los 90 se caracterizó por una politicidad joven asociada a prácticas culturales (Citro, 2008; Kropff y Núñez, 2012) o bien a formas no institucionales de movilización social (Bonvillani et al., 2010). Esa militancia habría recobrado canales tradicionales como los partidos políticos en los últimos años (Bonvillani et al., 2010; Kropff y Núñez, 2012).

\section{Referencias}

ALABARCES, P. Ponencia presentada en el Panel “Cromañón, Juventud y Rocanrol". In: ROZENGARDT, D. (Comp.). Debates a la orilla de la muerte joven: rock, política y derechos humanos. Buenos Aires: Equipo de Trabajo de Pensar Cromañón, 2008.

BENEDETTI, C. El rock de los desangelados: música, sectores populares y procesos de consumo. TRANS: Revista Transcultural de Música, n. 12, 2008. Disponible en: http://www.sibetrans.com/trans/p3/trans-12-2008. Acceso en: mayo 2013.

BONVILLANI, A.; PALERMO, A.; VÁZQUEZ, M.; VOMMARO, P. Del Cordobazo al kirchnerismo: una lectura crítica acerca de los períodos, temáticas y perspectivas en los estudios sobre juventudes y participación política en la Argentina. In: ALVARADO, S. V.; VOMMARO, P. (Comps.). Jóvenes, cultura y política en América Latina: algunos trayectos de sus relaciones, experiencias y lecturas (1960-2000). Rosario: Homo Sapiens Ediciones, 2010.

BOURDIEU, P. La juventud no es más que una palabra. In:______. Sociología y cultura. México: Grijalbo, 1990.

CITRO, S. El rock como un ritual adolescente: transgresión y realismo grotesco en los recitales de Bersuit. TRANS: Revista Transcultural de Música, n. 12, 2008. Disponible en: http://www.sibetrans.com/trans/p3/trans-12-2008. Acceso en: mayo 2013.

CHAVES, M. Investigaciones sobre juventudes en Argentina: estado del arte en ciencias sociales 19832006. Papeles de Trabajo, n. 5, 2009. Disponible en: http://www.idaes.edu.ar/papelesdetrabajo/paginas/ Documentos/05_15_Informedeinvestigacion_ MarianaChaves.pdf. Acceso en: nov. 2013.

CLARKE, J.; HALL, S.; JEFFERSON, T.; ROBERTS, B. Subculturas, culturas y clase. In: PÉREZ ISLAS, J. A.; VALDEZ GONZÁLEZ, M.; SUÁREZ ZOZOYA, M. (Coords.). Teorías sobre la juventud: las miradas de los clásicos. México: UNAM-CIIJ-Porrúa, 2008.

CRIVELLI, N. Juventud en riesgo: un estudio sobre la comunicación de las víctimas en el caso Cromañón. Tesina (Licenciatura en Ciencias de la Comunicación) -
El proceso en torno al incendio de Cromañón muestra que esas modalidades, posiblemente mayoritarias, conviven con otras expresiones que se mantuvieron asociadas a espacios como una murga o grupos seguidores de una banda de rock. Más allá de estas formas, quedan abiertas preguntas acerca de lo que aquella defensa del rock y la persistencia de estos modos de politicidad nos están diciendo sobre esos jóvenes. O bien, queda pensar con estos pibes sobre sus propias metáforas.

Universidad de Buenos Aires, Buenos Aires, 2007.

DURHAM, D. Los jóvenes y la imaginación social en África: introducción a las partes 1 y 2. Cuadernos de Antropología Social, n. 32, p.53-69, 2011.

FEIXA, C. De jóvenes, bandas y tribus (Antropología de la juventud). Barcelona: Ariel, 1998.

Generación XX: teorías sobre la juventud en la era contemporánea. Revista Latinoamericana de Ciencias Sociales, Niñez y Juventud, v. 4, n. 2, 2006. Disponible en: http://www.usc.es/cpoliticas/file.php/35/manuel_ torres/Feixa_2006_Generacion_XX_Teorias_juventud_ contemporaneas.pdf. Acceso en: abr. 2013.

GROPPO, L. A. Juventude: ensaios sobre sociologia e história das juventudes modernas. Rio de Janeiro: DIFEL, 2000 .

ISACOVICH, P. Tramas políticas, lazos de parentesco y genealogías de la movilización social: el caso de los familiares, amigos y sobrevivientes de Cromañón. Revista de la Escuela de Antropología, n. XVI, p.185-199, 2010.

KROPFF, L.; NÚÑEZ, P. Eje acción, participación, opciones y estrategias políticas. In: ZAFFARONI, A. (Comp.). Estudio sobre juventudes en Argentina II: líneas prioritarias de investigación en el área jóvenes/juventud. La importancia del conocimiento situado. Salta: Universidad Nacional de Salta, 2012.

MANZANO, Valeria. Ha llegado la "nueva ola": música, consumo y juventud en la Argentina, 1956-1966. In: COSSE, I.; FELITTI, K.; MANZANO, V. (Eds.). Los '60 de otra manera: vida cotidiana, género y sexualidades en la Argentina. Buenos Aires: Prometeo Libros, 2010.

MANZANO, Virginia. La política en movimiento: movilizaciones colectivas y políticas estatales en la vida del Gran Buenos Aires. Rosario: Prohistoria Ediciones, 2013. PALTI, E. J. El tiempo de la política: el Siglo XIX reconsiderado. Buenos Aires: Siglo XXI Editores Argentina, 2007.

SOUTO KUSTRÍN, S. Juventud, teoría e historia: la formación de un sujeto social y de un objeto de análisis. Historia Actual Online, n. 13, p. 171-192, 2007.

SOUILLA, S. El silencio de los jóvenes: estridencias y voces 
mudas en el tratamiento de República Cromañón en Crónica y Clarín. [S/f]. Disponible en: <http://74.125.47.132/ search?q=cache: XM_Nzv8QPegJ:www.unlar.edu.ar/ redcom/out/Croma\%C3\%B1\%C3\%B3n\%2520Souilla. $\mathrm{pdf}+$ susana + souilla\&hl $=\mathrm{es} \& \mathrm{ct}=\mathrm{clnk} \& \mathrm{~cd}=7>$. Acceso en: nov. 2012.

VILA, P. Rock nacional, crónicas de la resistencia juvenil. In: JELIN, E. (Comp.). Los nuevos movimientos sociales. Vol. 1, n. 124. Buenos Aires: CEAL, 1985.
Identidades narrativas y música: una primera propuesta para entender sus relaciones. TRANS: Revista Transcultural de Música, n. 2, 1996. Disponible en: <http:// www.sibetrans.com/trans>. Acceso en: ago. 2012.

WORTMAN, A. Una tragedia más, ahora los jóvenes y niños de la República Cromañón. Argumentos, n. 5, 2005. Disponible en: <www.revistasiigg.sociales.uba.ar/index. php/argumentos/issue/view/6>. Acceso en: out. 2009.

\title{
Youth as a political language: thoughts from the fire at a rock concert
}

\begin{abstract}
In Argentina, the association between rock and youth exists since the middle of the last century and this relationship has been variable political contents over time. The academic discussion of this relationship was revived after 2004, when a fire broke out during a rock concert and killed many young people. This resulted in a set of family, friends and survivors of the tragic event who had mobilized themselves and claimed justice. This work results of an anthropological research, and inquires about the place of youth in the political conflict developed around the fire, which was structured between adults. The analysis will show how stereotyped speeches on youth construct and legitimize political positions and practices, expressing metaphorically social issues that affect people of different ages. At the same time, the article opens questions about what young people have to say in their own languages.
\end{abstract}

Key words: youth, rock, politics, political languages.

\section{A juventude como linguagem política: reflexões a partir do incêndio em um show de rock}

\section{Resumo}

\begin{abstract}
$\mathrm{Na}$ argentina, a associação entre o rock e a juventude se remonta a meados do século passado, e esta relação não esteve isenta de conteúdos políticos variáveis. A discussão acadêmica sobre ela foi retomada após 2004, quando, durante um show de rock, um incêndio acabou com a vida de muitos jovens. O fato mobilizou sobreviventes, familiares e amigos das vítimas a exigir justiça. Assim, este artigo, produto de investigação antropológica, indaga o lugar da juventude no conflito político desenvolvido em torno do incêndio. A análise mostra como os discursos estereotipados sobre os jovens constroem e legitimam práticas e posições políticas, expressando metaforicamente problemáticas sociais que afetam a população sem distinção de idade. Além disso, ela deixa perguntas sobre o que os jovens, em seu próprio linguajar, têm a dizer sobre o trágico acontecimento.
\end{abstract}

Palavras-chave: juventude, rock, política, linguajares políticos.

Data de recebimento do artigo: 9/12/2013

Data de aprovação do artigo: 6/8/2014 